\title{
Probiotic Screening and Safety Evaluation of Lactobacillus Strains from Plants, Artisanal Goat Cheese, Human Stools, and Milk
}

\author{
Martin Gotteland, ${ }^{1,2}$ Maria-Jose Cires, ${ }^{1,2}$ Claudia Carvallo, ${ }^{1}$ Natalia Vega, \\ Maria-Antonieta Ramirez, Pamela Morales, ${ }^{1,2}$ Patricia Rivas, ${ }_{1}^{1}$ Fernanda Astudillo, \\ Paola Navarrete, ${ }^{3}$ Céline Dubos, ${ }^{1}$ Alvaro Figueroa, ${ }^{1}$ Miriam Troncoso, ${ }^{1}$ Carolina Ulloa, \\ Maria-Luisa Mizgier, ${ }^{1}$ Catalina Carrasco-Pozo, ${ }^{1,2}$ Hernan Speisky, ${ }^{4}$ \\ Oscar Brunser, and Guillermo Figueroa ${ }^{1}$ \\ ${ }^{1}$ Laboratory of Microbiology and Probiotics, Institute of Nutrition and Food Technology (INTA), \\ University of Chile, Santiago, Chile. \\ ${ }^{2}$ Department of Nutrition, Faculty of Medicine, University of Chile, Santiago, Chile. \\ Laboratory of ${ }^{3}$ Biotechnology and ${ }^{4}$ Antioxidant, Institute of Nutrition and Food Technology (INTA), \\ University of Chile, Santiago, Chile.
}

\begin{abstract}
The aim of this study was to select autochthonous strains of Lactobacillus from stools of healthy infants and adults, human milk, artisanal goat cheese, and fruits and vegetables according to their probiotic properties and safety. From 421 strains of Lactobacillus isolated, $102(24.2 \%)$ were shown to be tolerant to gastric $\mathrm{pH}$ and bile salts; they were used to determine their anti-Helicobacter pylori (agar diffusion assay), antioxidant (oxygen radical absorption capacity), and antiinflammatory (inhibition of interleukin- 8 release by tumor necrosis factor- $\alpha$-stimulated HT-29 cells) activities as well as their ability to adhere to intestinal (Caco-2) and gastric (AGS) cells. Results obtained were compared with three commercial probiotic Lactobacilli rhamnosus GG, L. plantarum 299v, and L. johnsonii NCC533. The five strains most efficient according to these activities were subsequently identified by sequencing their 16S rRNA gene, their susceptibility to antibiotics determined, and their safety evaluated in mice. One strain of $L$. plantarum was discarded due to the higher prevalence of liver translocation observed in the animals fed this strain. In conclusion, four autochthonous strains of L. rhamnosus were finally selected with probiotic properties and safety allowing their eventual use in human studies. These results contribute to increase the diversity of probiotic strains available for the development of nutraceuticals and functional foods.
\end{abstract}

KEY WORDS: • anti-inflammatory $\bullet$ antimicrobial activity $\bullet$ antioxidant capacity $\bullet$ Lactobacillus (acidophilus, bulgaricus, and others) $\bullet$ probiotics

\section{INTRODUCTION}

$\mathbf{L}$ ACTOBACILLI ARE LACTIC acid bacteria widely used for the elaboration of fermented foodstuffs such as cheese, yogurt, sauerkraut, dry sausages, pickles, and silage for animal feeding. During the fermentation process, the production of short-chain organic acids decreases the environmental $\mathrm{pH}$ and inhibits pathogenic bacteria, in addition to the generation of new flavors attractive for the consumers. Some species of Lactobacillus present in fermented products are also frequent members of the autochthonous microbiota of the gastrointestinal and the urogenital tracts and are even present in

\footnotetext{
AU3 Supported by Innova-Corfo 07CN13PZT-13.

Manuscript received 1 February 2012. Revision accepted 7 October 2013.
}

Address correspondence to: Martin Gotteland, PhD, Department of Nutrition, Faculty of Medicine, University of Chile, Independencia 1027, Independencia, Santiago 13811, Chile,E-mail:mgottela@med.uchile.cl maternal milk. ${ }^{1,2}$ Lactobacilli are generally recognized as safe microorganisms and, together with bifidobacteria, are considered as the hallmark of a healthy microbiota in these body compartments. However, only a discrete number of Lactobacillus strains are considered as probiotics, defined by the FAO/WHO as "Live microorganisms which, when administered in adequate numbers, confer a health benefit to the host." 3 Probiotics are generally well accepted by the consumers and, in addition to dairy products, they are increasingly added to a growing number of foodstuffs such as infant formula, ice cream, chocolate, cereals, and fruit and vegetable juices. Healthy foods are increasingly demanded by educated consumers and the global market for probiotics is one of the fastest growing segments of the dietary supplement and functional food industry. It is estimated that the compound annual growth rate of the probiotic market ranges from $5 \%$ to $30 \%$ depending on the country and product type, with an expected market value of $\$ 31$ billion in $2015 .{ }^{4}$ Taking into 
account these antecedents and the fact that the healthpromoting effects of the probiotics are strain specific, there is a considerable interest in increasing the number of available probiotic strains and products with new health properties based on their mechanism of action. This study describes the first step in the selection of local probiotic strains of Lactobacillus initially isolated from stools of healthy infants and adults, human milk, artisanal goat cheese, and fruits and vegetables in Chile.

\section{MATERIALS AND METHODS}

\section{Preliminary isolation and identification of Lactobacilli}

Lactobacilli were isolated from fruits and vegetables, artisanal goat cheese, human milk, and human feces.

The fruits and vegetables (corn, broccoli, pickles, cucumber, artichoke, banana, and gherkin) were bought in the local food markets. Sterile swabs moistened in a saline solution were used to wash the surface of the plant material

AU5 and were subsequently spread on MRS agar plates (a selective medium for Lactobacillus sp.).

The Lactobacilli from cheese were isolated in a previous study carried out by our laboratory to characterize the biodiversity of the lactic microbiota from artisanal goat cheese elaborated in the Fourth Region (Coquimbo) in Chile. More than 60 samples of crude goat milk and ripened cheese obtained from different manufacturers were processed; about $25 \mathrm{~g}$ of cheese were homogenized in sterile peptone water $0.1 \%$, serially diluted, and $100 \mu \mathrm{L}$ of each dilution was plated on MRS agar.

The Lactobacilli of fecal origin were initially isolated during clinical trials previously carried out in our laboratory in infants and adults. ${ }^{5-8}$ In these trials, healthy subjects were recruited and the antecedents of previous intake of probiotics, antibiotics, laxatives, or other drugs potentially interfering with their intestinal microbiota were considered exclusion criteria. Stool samples were obtained before the beginning of the administration of the treatment and were processed, at the most, $2 \mathrm{~h}$ after their emission. About $1 \mathrm{~g}$ of stool was serially diluted in sterile phosphate-buffered saline (PBS) and $100 \mu \mathrm{L}$ of the dilution was plated on MRS agar.

For the isolation of Lactobacilli from human milk, 116 healthy mothers of at-term infants and without any pharmacological treatments were recruited at the Hospital Luis Tisne Maternity Ward in South-East of Santiago. ${ }^{2}$ Two milliliter samples of colostrum were collected aseptically in duplicate by a registered nurse during the first 2 days of the postpartum and maintained at $4^{\circ} \mathrm{C}$ until their processing in the laboratory (at the most $2 \mathrm{~h}$ after their emission). Samples were diluted in sterile PBS and spread on MRS agar.

The protocol of all studies in which humans participated had been reviewed and accepted by the Ethics Committee of INTA, University of Chile and written informed consent was obtained from the recruited subjects before their participation.

All samples seeded in MRS agar were incubated at $37^{\circ} \mathrm{C}$ for 48-72 $\mathrm{h}$ under anaerobic conditions. Characteristic colonies were selected and processed for Gram staining and bacterial morphology examination. Gram-positive bacteria with Lactobacillus-like morphology were assayed for catalase activity, indole production, and motility. Microorganisms negative for the three tests were considered as potential Lactobacillus spp. strains. The isolated strains were resuspended in an MRS broth $15 \%$ glycerol and/or in skim milk $(20 \%)$ and kept at $-30^{\circ} \mathrm{C}$ until subsequent analysis.

In the following studies, the presumed Lactobacillus strains evaluated were compared, under the same experimental conditions, with at least one of the three commercial probiotic strains used as positive controls: L. johnsonii NCC533, L. plantarum 299v, and/or L. rhamnosus GG.

\section{Resistance to gastric $\mathrm{pH}$ and bile salts}

To evaluate the resistance of the Lactobacillus strains to gastric lumen conditions, a standardized inoculum $\left(\sim 10^{8}\right.$ $\mathrm{UFC} / \mathrm{mL})$ was added to artificial gastric juice $(\mathrm{NaCl} 0.2 \%$, pepsine $0.32 \%$ [w/v], $\mathrm{pH} 2,0$ adjusted with $\mathrm{HCl}$ ) and incubated at $37^{\circ} \mathrm{C}$ for $90 \mathrm{~min}$. Thereafter, serial dilutions were carried out in sterile saline $(0.85 \%)$, plated on MRS agar plates, and incubated at $37^{\circ} \mathrm{C}$ for $72 \mathrm{~h}$ under anaerobic conditions. Strains were defined as resistant when their initial concentrations did not decrease by more than one log during the time course of the incubation.

On the other hand, a standardized inoculum of the bacteria was cultured in the MRS broth containing $0.4 \%$ bile salts (Oxgal) for $4 \mathrm{~h}$ at $37^{\circ} \mathrm{C}$ in a microaerophilic atmosphere. Bacterial counts were carried out in MRS agar at $37^{\circ} \mathrm{C}$ for $48 \mathrm{~h}$ under anaerobic conditions. Resistant strains were defined as those whose initial concentrations did not decrease by more than one log during the incubation.

The strains of Lactobacillus resistant to gastric $\mathrm{pH}$ and bile salts were selected for evaluation of their antibacterial, antioxidant, anti-inflammatory, and adhesion properties.

\section{Inhibitory activity against Helicobacter pylori}

Two strains of Helicobacter pylori, ATCC 43504 and a local strain (TX-136) isolated from a gastric biopsy in a patient with duodenal ulcer (both expressing the vacA and cagA virulence toxins), were used as targets to determine the inhibitory activity of the Lactobacilli in an agar diffusion assay. Fresh cultures of both the $H$. pylori strains were spread on antibiotic-free blood agar and $5 \mu \mathrm{L}$ of the Lactobacillus strain culture was deposited as spots on the agar. The plates were incubated at $37^{\circ} \mathrm{C}$ under microaerophilic conditions for $72 \mathrm{~h}$ and the diameters of inhibition zones were measured. The assays were carried out in duplicate.

In addition, the capacity of the Lactobacilli to inhibit the urease activity of $H$. pylori was also determined. A standardized inoculum of the $H$. pylori strain was incubated with the supernatants of the Lactobacillus strains (adjusted at $\mathrm{pH}$ 4.5 and 6.5$)$ in a urea broth $(20 \mathrm{~g} / \mathrm{L})$ with phenol red $(0.01 \mathrm{~g} / \mathrm{L})$ for $24 \mathrm{~h}$ at $37^{\circ} \mathrm{C}$ in 96 -well microplates. The urea broth with the $H$. pylori strain and ampicillin $(25 \mu \mathrm{g} / \mathrm{mL})$ was used as positive control of inhibition and the urea broth alone with $H$. pylori as negative control. Changes in $\mathrm{OD}_{550}$ were determined during the time course of the incubation period. 
The presence of inhibitory activity was defined by the absence of OD changes.

\section{Anti-inflammatory activity}

The anti-inflammatory activity was determined using HT29 intestinal cells, as described elsewhere. ${ }^{9}$ The cells were

AU5 cultured in the DMEM/F12 medium containing $10 \%$ fetal calf serum with antibiotic at $37^{\circ} \mathrm{C}$ until confluence. Cells were washed and incubated in a serum-free medium without antibiotic in the presence of tumor necrosis factor- $\alpha$ (TNF- $\alpha$, $40 \mathrm{ng} / \mathrm{mL}$ ) and an aliquot of the supernatants of standardized Lactobacillus cultures $\left(10 \mathrm{~h}\right.$ at $\left.37^{\circ} \mathrm{C}\right)$. The anti-inflammatory activity was determined in triplicate and as the percentage of inhibition of interleukin (IL)-8 release induced by TNF- $\alpha$ compared with the control without a supernatant.

\section{Determination of the antioxidant activity}

Selected Lactobacillus strains were cultured in the MRS broth for $16 \mathrm{~h}$ and the resulting bacterial suspensions were washed two times in sterile PBS and standardized at a concentration of $10^{9}$ colony forming unit $(\mathrm{CFU}) / \mathrm{mL}$. The suspensions were ultrasonicated on ice to release their intracellular content and centrifuged at $4^{\circ} \mathrm{C}$. The supernatants were used to determine the antioxidant activity through the determination of the oxygen radical absorption capacity (ORAC) assay.

ORAC was carried out following the method described by Cao et $a l .{ }^{10}$ with slight modifications, by measuring the ability of the samples to inhibit the decline in fluorescein (FL) fluorescence induced by the peroxyl radical generator 2,2'-azobis-2-methyl-propanimidamide dihydrochloride (AAPH; Sigma). The reaction mixture contained $70 \mathrm{nM}$ FL and $18 \mathrm{mM}$ AAPH in a final volume of $270 \mu \mathrm{L}$ of a $120 \mathrm{mM}$ phosphate buffer ( $\mathrm{pH}$ 7.4). FL, phosphate buffer, and the bacterial supernatant were preincubated at $37^{\circ} \mathrm{C}$ for $20 \mathrm{~min}$. The reaction was started by the addition of AAPH and fluorescence intensity was recorded every $3 \mathrm{~min}$ (485Ex/ $520 \mathrm{Em}$ ) using a microplate reader (Synergy HT; Biotek Instruments) until the fluorescence of the last reading declined to a value lower than $5 \%$ of the first reading. The raw data were exported to a GraphPad Prism 4 sheet to calculate the area under the curve of FL decay; results were expressed as $\mu$ mole of trolox equivalent (TE)/L.

\section{Adhesion to intestinal and gastric epithelial cells}

The adhesion to Caco2 intestinal cells was determined for the 102 strains of Lactobacillus resistant to $\mathrm{pH}$ and bile salts, while the adhesion to AGS gastric cells was evaluated only with those strains with exhibited antibacterial, antioxidant, and/or anti-inflammatory activities. Caco-2 and AGS cells were cultured in the DMEM/F12 medium containing $10 \%$ fetal calf serum with antibiotic at $37^{\circ} \mathrm{C}$ in 96 -well microplates. Confluent cells were incubated for $1 \mathrm{~h}$ at $37^{\circ} \mathrm{C}$ with each strain of Lactobacillus at a concentration of $\sim 10^{7}$ $\mathrm{CFU} / \mathrm{mL}$. After the incubation, the cells were washed four times with sterile PBS to eliminate nonadhering bacteria and lyzed with $0.3 \%$ Triton. The lysates were serially diluted in PBS and $100 \mu \mathrm{L}$ of the dilutions was spread on MRS agar and incubated for $48 \mathrm{~h}$ at $37^{\circ} \mathrm{C}$ in anaerobic conditions. Cells grown in control wells without bacteria were trypsinized and the mean number of living Caco2 cells per well was determined in a cell counting chamber after Trypan Blue staining. Results were expressed as the percentage of adhering bacteria in relation with the total number of bacteria added into the well at the beginning of the experiment.

\section{Lactobacillus identification by $16 \mathrm{~S}$ rRNA gene sequencing}

The 102 strains of Lactobacillus resistant to $\mathrm{pH}$ and bile salts were ranked according to the results of their antibacterial, antioxidant, anti-inflammatory, and adherence properties and the five most efficient strains were selected for sequencing. Their bacterial DNA were extracted from $1 \mathrm{~mL}$ of overnight culture and the $16 \mathrm{~S}$ rRNA gene was subsequently amplified by polymerase chain reaction (PCR) using the following primers: 27F: $5^{\prime}$ AGA GTT TGA TCM TGG CTC AG $3^{\prime}$ and 1492R: $5^{\prime}$ TAC GGY TAC CTT GTT ACG ACT T $3^{\prime} .^{2}$ The PCR products were separated in $1 \%$ agarose gel, purified, and subsequently sequenced (Macrogen USA sequencing service). The Lactobacillus species were identified by comparing their sequences with those from the Ribosomal Database Project (http://rdp.cme.msu.edu/).

\section{Antibiotic susceptibility and safety evaluation}

The susceptibility to antibiotics of the five selected strains as well as their safety in animals were determined. ${ }^{11}$ The antibiotic susceptibility was carried out using the agar diffusion method (CLSI) adapted from Charteris et al. ${ }^{12}$ The diameter of the inhibition was measured after $24 \mathrm{~h}$ of incubation at $37^{\circ} \mathrm{C}$ in anaerobic conditions and compared with the CLSI 2009 tables. Escherichia coli ATCC 25922 were used as control strain ${ }^{13}$ and commercial probiotics were used as references.

For the evaluation of safety, male BALB/c mice aged 6-8 weeks (17-21 g) (Public Health Institute) were acclimatized for 2 weeks before the test in the animal housing facilities of INTA, with ad libitum access to water and food. The experimental protocol was accepted by the Committee on Ethics in Animals of INTA. Eight groups of animals $(n=6-11)$ were used: groups 1 and 2 were positive control groups treated with commercial probiotic strains (L. rhamnosus GG or L. plantarum 299v), while groups 3-7 were experimental groups challenged with each one of the five strains selected in this study. For administration, all bacterial strains were resuspended in $10 \%$ skim milk at a concentration $\sim 10^{11}$ $\mathrm{CFU} / \mathrm{ml}$. Group 8 was the negative control group, treated with the vehicle (10\% skim milk powder). A volume of 50 $\mu \mathrm{L}$ of the bacterial suspension was administered intragastrically with a gavage needle twice daily at 4-h intervals for 7 consecutive days. The negative control group received the same amount of milk without the bacterial strains. The animals were then subjected to a 1 -week washout period without treatment. Mice were weighted 
before and after treatment and at the end of the washout period and their condition (coat, somnolence, activity, stress, and diarrhea) was evaluated daily throughout the course of the study. At the end of the washout period, the animals were anesthetized with diethyl ether and blood samples were obtained by cardiac puncture to quantitate hematological parameters. Mice were then sacrificed by cervical dislocation, washed with $95 \%$ ethanol, and a laparotomy was carried out in a laminar flow cabinet to extract aseptically mesenteric lymph nodes, liver and spleen samples. These tissue samples were homogenized in sterile PBS and aliquots of the homogenates were spread on MRS agar and brain heart $(\mathrm{BH})$ agar (an enriched nonselective medium for aerobic and anaerobic bacteria) plates and incubated anaerobically for $48 \mathrm{~h}$ at $37^{\circ} \mathrm{C}$ to determine the presence of microorganisms, suggestive of bacterial translocation. ${ }^{14}$ Results were expressed as the prevalence of bacteria in the samples, that is, the number of samples with detected bacteria/total samples. On the other hand, samples of terminal ileum, cecum, and proximal colon were also excised to evaluate possible damage to their mucosa through their histologic evaluation by a trained pathologist blinded to the treatments administered.

\section{Statistical analysis}

Results are expressed as mean \pm standard deviation (SD) or as median \pm interquartil range (IQR) according to the parametric or nonparametric distribution of the variables. When necessary, comparisons between groups were carried out by using the Mann-Whitney nonparametric test. Changes in weight of the animals in the safety study were compared between groups by analysis of variance for repeated measurements. Prevalence of bacteria in the tissue samples was analyzed by the Fisher test.

\section{RESULTS}

Lactobacillus spp. isolation and evaluation of gastric $\mathrm{pH}$ and bile salt resistance

A total of 421 strains of presumed Lactobacillus spp. were isolated and characterized: 234 from stool samples, 132 from human milk samples, 46 from artisanal goat cheese, and 9 from fruits and vegetables. The microorganisms isolated were selected initially on the basis of their capacity to survive incubation with artificial gastric juice or bile salts. Of the 421 strains evaluated, 102 (24.2\%) were resistant to the conditions comparable to the gastric juice and to the bile salts: 60 (25.6\%) from human stool, $29(22 \%)$ from human milk, $10(21.7 \%)$ from artisanal goat cheese, and $3(33.3 \%)$ from fruits and vegetables. No differences as related to their origin were observed $(P=.76)$. These 102 strains were posteriorly used for the subsequent selection procedures.

\section{Antibacterial activity against anti $H$. pylori}

The antibacterial activity of the 102 selected strains of Lactobacillus was evaluated using the agar diffusion assay with a reference strain of $H$. pylori from ATCC (Ref 443504) and a local clinical isolate (TX-136) as targets. The inhibition halo was measured after $72 \mathrm{~h}$ of incubation. The positive control strain $L$. johnsonii NCC533 inhibited both strains of $H$. pylori as well as their urease activity, while L. rhamnosus GG and L. plantarum $299 \mathrm{v}$ were less efficient. Six out of the 102 strains evaluated $(5.9 \%)$ inhibited both target strains, 7 (6.9\%) inhibited only one $H$. pylori strain and 4 exhibited a low antibacterial activity (Table 1). These 17 strains also inhibited the urease activity of both strains of H. pylori at $\mathrm{pH} 4.5$. At $\mathrm{pH} 6.5,14$ of them (82\%) inhibited the urease activity of the ATCCC 443504 strain, while only $10(59 \%)$ was effective against the urease activity of the TX 136 strain.

\section{Anti-inflammatory activity}

The anti-inflammatory activity of the 102 strains of Lactobacillus strains was evaluated as the percentage of inhibition of IL- 8 release by TNF- $\alpha$-stimulated HT-29 cells. Seven strains $(6.9 \%)$ inhibited IL- 8 release by more than $75 \%$ and 13 showed a moderate effect $(50-75 \%$ of inhibition), similar to that observed with the probiotic strain L. johnsonii NCC533 (58.0 $\pm 7.2 \%$ of inhibition). The remaining strains had little or no effect or even, in some cases (10 strains), stimulated IL-8 release.

\section{Antioxidant activity}

Taking as cutoff point the mean value of the three commercial probiotic strains (L. johnsonii NCC533, L. rhamnosus GG, and L. plantarum 299v) used as controls $(4.30 \pm 1.95 \mu \mathrm{mol} \mathrm{TE} / \mathrm{L}) \pm 2 \mathrm{SD}$, nine strains of Lactobacillus with antioxidant activity were detected (Table 2).

\section{Adhesion to intestinal and gastric epithelial cells}

The adhesion of selected Lactobacillus strains to Caco-2 intestinal cells was expressed as the percentage of adhering bacteria in relation with the number of bacteria initially present in the well. The median value of adhesion for the 102 strains evaluated was $0.28 \%$ [0.08-1.30\%] ([IQR]). An adhesion rate greater than $2.5 \%$ was observed in 12 of the 102 strains $(11.8 \%)$, similar to that observed by the probiotic L. johnsonii NCC533 (4.43 $\pm 0.52 \%)$, while it was moderate (between $1 \%$ and $2.5 \%$ ) in $18(17.7 \%$ ) and low in the remaining strains. Adhesion to gastric cells was evaluated only in the strains displaying anti-inflammatory, antioxidant, or/and anti-H. pylori activities. The median value of adhesion was $1.33 \%$ [0.19-3.01\%] ([IQR]) and two strains had an adhesion rate greater than $2.5 \%$.

\section{Selection and genotyping}

Strains were ranked taking into account the results previously described and the five strains with the highest ranking were selected for genotyping through PCR sequencing. As shown in Table 3, four strains are L. rhamnosus species and one L. plantarum, four of them originating from human stools and one from an artisanal goat cheese. 
Table 1. Strains of LaCtobacillus SPP. With Anti-HelicobaCter PYlori Activity

\begin{tabular}{|c|c|c|c|c|c|c|c|}
\hline \multirow[b]{3}{*}{ Strains of Lactobacillus spp. } & \multirow[b]{3}{*}{ Origin } & & & \multicolumn{4}{|c|}{ Inhibition of urease activity } \\
\hline & & \multicolumn{2}{|c|}{ Anti-Helicobacter pylori activity } & \multicolumn{2}{|c|}{ ATCC 443504} & \multicolumn{2}{|c|}{$T X-136$} \\
\hline & & ATCC 443504 & $T X-136$ & $p H 4.5$ & pH 6.5 & $p H 4.5$ & pH 6.5 \\
\hline L. johnsonii NCC533 & Commercial & + & + & + & + & + & + \\
\hline L. rhamnosus $G G$ & Commercial & - & + & + & - & + & + \\
\hline L. plantarum 299v & Commercial & - & - & + & + & + & + \\
\hline 17 & Human stool & + & + & + & + & + & + \\
\hline 20 & Human stool & + & + & + & + & + & - \\
\hline 27 & Human stool & - & + & + & + & + & + \\
\hline 70 & Human stool & + & + & + & + & + & + \\
\hline 77 & Human stool & + & + & + & + & + & + \\
\hline $40 \mathrm{~B}$ & Human stool & - & + & + & + & + & - \\
\hline $45 \mathrm{~B}$ & Human stool & + & - & + & + & + & - \\
\hline $75^{\prime}$ & Human stool & - & + & + & - & + & - \\
\hline F152-8 & Human stool & - & + & + & + & + & + \\
\hline ISVI-A & Human stool & - & + & + & + & + & - \\
\hline N145-1 & Human stool & + & + & + & + & + & - \\
\hline D111-2 & Human stool & - & $+1-$ & + & - & + & + \\
\hline D113-4 & Human stool & $+1-$ & $+1-$ & + & + & + & + \\
\hline VISA & Human stool & - & + & + & + & + & + \\
\hline L55-2-35 & Maternal milk & $+1-$ & - & + & + & + & + \\
\hline L60-1-13 & Maternal milk & $+1-$ & - & + & - & + & - \\
\hline POR-601 & Fruits/vegetables & - & + & + & + & + & + \\
\hline
\end{tabular}

-, Absence of halo of inhibition; +/-, presence of a weak halo of inhibition; +, presence of a large halo of inhibition.

Their individual values for anti-H. pylori, antioxidant, antiinflammatory, and adhesive properties are also shown in the Table.

\section{Antibiotic susceptibility}

The antibiotic susceptibility of the five selected strains is shown in Table 4. All the strains were resistant to nalidixic acid, streptomycin, and vancomycin and sensitive to erythromycin, rifampicin, chloramphenicol, and penicillin G. Eighty percent were sensitive to cefazolin and tetracycline and $20 \%$ to sulfa-trimethoprim.

Table 2. Antioxidant Activity (Oxygen Radical Absorption CAPACITY) In LaCtobacillus Strains

\begin{tabular}{llc}
\hline Lactobacillus strains & Origin & $\begin{array}{c}\text { Antioxidant activity } \\
(\text { ORAC })(\mu m o l ~ T E / L)\end{array}$ \\
\hline L. johnsonii NCC533 & Commercial & $2.73 \pm 0.8$ \\
L. rhamnosus GG & Commercial & $6.49 \pm 0.7$ \\
L. plantarum 299v & Commercial & $3.68 \pm 0.4$ \\
Mean control strains & & $4.30 \pm 1.95$ \\
SAVI & Human stool & $8.94 \pm 0.6$ \\
45B & Human stool & $17.4 \pm 0.8$ \\
AIES-B & Human stool & $10.34 \pm 0.2$ \\
F54-1B & Human stool & $9.98 \pm 0.5$ \\
N221-1 & Human stool & $8.74 \pm 0.3$ \\
QF60-2 & Goat cheese & $11.49 \pm 0.3$ \\
QF96-1 & Goat cheese & $9.08 \pm 0.9$ \\
L30-2-17 & Human milk & $10.85 \pm 0.8$ \\
L63-1-25 & Human milk & $10.59 \pm 0.7$
\end{tabular}

ORAC, oxygen radical absorption capacity; TE, trolox equivalent.

\section{Evaluation of safety in mice}

The condition of the animals was not affected by the treatments (data not shown). The analysis of variances for repeated measurements did not detect any differences in weight changes between the experimental groups and the control group (skim milk) or the groups that were administered the commercial probiotic strains (L. rhamnosus GG or L. plantarum 299v) (Data not shown).

The histological analysis indicates that the thickness of the mucosae in the control animals was $259.2 \pm 28.1 \mathrm{~nm}$, $129.1 \pm 12.8 \mathrm{~nm}$, and $108.8 \pm 73 \mathrm{~nm}$ for the ileal, cecal, and colonic samples, respectively. No alterations in these parameters were observed in the groups receiving $L$. rhamnosus GG or L. plantarum 299v. In particular, the integrity of the epithelium was not affected and infiltration of neutrophils or monocytes/macrophages in the lamina propria was not detected nor was edema or venous congestion (data not shown). No changes in the thickness of the cecal and colonic mucosa were observed in the experimental groups compared with the control group or the groups receiving LGG or Lp299v. Only a significant increase of the thickness of the ileal mucosa was observed in the animals administered with the N145 $(287.4 \pm 20.4 \mathrm{~nm} ; P<.05)$ and the $20(297.4 \pm 18.5 \mathrm{~nm} ; P<.01)$ strains compared with the controls.

With respect to the hematological parameters of the animals, the erythrocyte concentration, mean corpuscular volume, hematocrit, hemoglobin concentration, and zinc protoporphyrin were not affected by the administration of the commercial probiotics (L. rhamnosus GG or L. plantarum 
Table 3. Characteristics of the Selected Strains of Lactobacillus in Relation to Their Antibacterial, Antioxidant, Anti-inflammatory, and Adhesive Properties

\begin{tabular}{|c|c|c|c|c|c|c|c|}
\hline AU9 & $\begin{array}{l}\text { Selected strains } \\
\text { of Lactobacillus }\end{array}$ & Origin & $\begin{array}{l}\text { Anti-H. pylori } \\
\text { activity }^{\mathrm{a}}\end{array}$ & $\begin{array}{c}\text { Antioxidant activity } \\
(\mu \mathrm{mol} T E / L)\end{array}$ & $\begin{array}{c}\text { Adhesion to } \\
\text { Caco-2 cells }(\%)\end{array}$ & $\begin{array}{c}\text { Adhesion to } \\
\text { AGS cells (\%) }\end{array}$ & $\begin{array}{c}\text { Anti-inflammatory } \\
\text { activity (\% of inhibition } \\
\text { of IL-8 release) }\end{array}$ \\
\hline & L. rhamnosus 20 & Human stool & ++ & $3.05 \pm 0.2$ & $2.01 \pm 0.08$ & $1.33 \pm 0.07$ & $76.3 \pm 3.5$ \\
\hline & L. rhamnosus 45B & Human stool & + & $17.4 \pm 0.8$ & $0.09 \pm 0.04$ & $3.01 \pm 0.32$ & $79.5 \pm 0.8$ \\
\hline & L. plantarum N221-1 & Human stool & - & $8.74 \pm 0.3$ & $0.25 \pm 0.06$ & $4.55 \pm 0.14$ & $83.0 \pm 5.2$ \\
\hline & L. rhamnosus N145-1A & Human stool & ++ & $6.60 \pm 0.5$ & $0.50 \pm 0.12$ & $1.63 \pm 0.07$ & $80.7 \pm 6.8$ \\
\hline & L. rhamnosus QF60-2 & Goat cheese & - & $11.49 \pm 0.3$ & $0.66 \pm 0.06$ & $4.62 \pm 0.08$ & $81.0 \pm 10.6$ \\
\hline
\end{tabular}

-, without activity; + , moderate activity; ++ , high activity.

$299 \mathrm{v})$ or by the selected strains and their values remained within the physiological range (data not shown). However, the white cell count was slightly below the physiological range in the group receiving $L$. rhamnosus 20 and this parameter was clearly decreased in the group receiving L. plantarum $\mathrm{N} 221$ compared with the control group $\left(3.80 \pm 1.78 \times 10^{3} / \mathrm{mm}^{3}\right.$ vs. $8.61 \pm 2.86 \times 10^{3} / \mathrm{mm}^{3}$, respectively), while no variations were detected in the other groups.

The prevalence of bacterial translocation, that is, the passage of bacteria across the epithelial monolayer from the gut lumen to the mesenteric lymph nodes, spleen, and liver, was determined by culturing samples of these tissues on a nonselective $\mathrm{BH}$ medium (allowing the detection of most of the cultivable bacteria) and on the MRS medium, selective for Lactobacillus sp. As shown in Table 5, bacteria were detected in $100 \%$ of lymph node samples from the vehicletreated animals and from the groups administered LGG or Lp299v, when cultured in the BH medium; however, the detection rate of bacteria was lower (0-18\%) when the samples were cultured on the MRS medium. The prevalence of bacteria (cultured either in the BH or MRS medium) in the lymph node samples of the animals treated with the strains selected in the current study was similar or lower than those observed with the commercial probiotics, except for the group treated with the L. plantarum N-221 strain, which shows a significantly higher rate of detection $(50 \%)$ in the MRS medium. The prevalence of bacteria in samples of spleen and liver cultured either in BH or MRS agar was lower or similar to that observed in lymph nodes. The presence of bacteria in samples cultured on MRS agar tended to be more frequent in the group treated with the strain L. plantarum N221-1 and in addition, the concentrations of bacteria were higher in this group than in the other groups (data not shown).

\section{DISCUSSION}

The aim of this study was to characterize strains of Lactobacillus isolated in Chile from different origins, according to the International Scientific Association for Probiotics and Prebiotics, ${ }^{15}$ which states that probiotics must "be alive when administered, have undergone controlled evaluation to document health benefits in the target host, be a taxonomically defined microbe or combination of microbes (genus, species and strain level), and be safe for its intended use." As a preamble, it is noteworthy that there are no official standardized methods to assess probiotic properties or safety and that in consequences, the methods generally used vary from study to study, increasing the variability of their results and creating uncertainty in comparing results.

An important criterion for the selection of potential probiotics is their capacity to resist gastric $\mathrm{pH}$ and bile salts and to adhere to epithelial surfaces, which determine their ability to remain alive and functional in the gastrointestinal tract of their host. ${ }^{16}$ Lactobacilli are naturally resistant to low $\mathrm{pH}$

Table 4. Antibiotic Resistance of the Five Selected Strains of Lactobacillus

\begin{tabular}{|c|c|c|c|c|c|c|c|c|}
\hline \multirow[b]{2}{*}{ Antibiotics } & \multicolumn{3}{|c|}{ Control strains } & \multicolumn{5}{|c|}{ Selected strains of Lactobacillus } \\
\hline & Lp 299v & $\operatorname{Lr} G G$ & Lj NCC533 & $\operatorname{Lr} 20$ & $\operatorname{Lr} 45 B$ & $\operatorname{Lr} N 145-1 A$ & Lp N221-1 & Lr QF60-2 \\
\hline Penicillin G (10 U) & MS & $\mathrm{S}$ & $\mathrm{S}$ & $\mathrm{S}$ & $\mathrm{S}$ & MS & S & MS \\
\hline Cefazolin $(30 \mu \mathrm{g})$ & $\mathrm{R}$ & $\mathrm{S}$ & $\mathrm{R}$ & $\mathrm{R}$ & $\mathrm{S}$ & $\mathrm{S}$ & MS & $\mathrm{S}$ \\
\hline Nalidixic acid $(30 \mu \mathrm{g})$ & $\mathrm{R}$ & $\mathrm{R}$ & $\mathrm{R}$ & $\mathrm{R}$ & $\mathrm{R}$ & $\mathrm{R}$ & $\mathrm{R}$ & $\mathrm{R}$ \\
\hline Tetracycline $(30 \mu \mathrm{g})$ & $\mathrm{S}$ & $\mathrm{S}$ & $\mathrm{S}$ & $\mathrm{S}$ & $\mathrm{S}$ & $\mathrm{S}$ & $\mathrm{S}$ & $\mathrm{R}$ \\
\hline Streptomycin $(10 \mu \mathrm{g})$ & $\mathrm{R}$ & $\mathrm{S}$ & $\mathrm{R}$ & $\mathrm{R}$ & $\mathrm{R}$ & $\mathrm{R}$ & $\mathrm{R}$ & $\mathrm{R}$ \\
\hline Rifampicin $(5 \mu \mathrm{g})$ & $\mathrm{S}$ & $\mathrm{S}$ & $\mathrm{S}$ & $\mathrm{S}$ & $\mathrm{S}$ & $\mathrm{S}$ & - & - \\
\hline Erythromycin $(15 \mu \mathrm{g})$ & $\mathrm{R}$ & $\mathrm{S}$ & $\mathrm{S}$ & $\mathrm{S}$ & $\mathrm{S}$ & $\mathrm{S}$ & $\mathrm{S}$ & $\mathrm{S}$ \\
\hline Chloramphenicol $(30 \mu \mathrm{g})$ & $\mathrm{S}$ & $\mathrm{S}$ & - & 一 & $\mathrm{S}$ & $\mathrm{S}$ & $\mathrm{S}$ & $\mathrm{S}$ \\
\hline Sulfa-trimethoprim $(25 \mu \mathrm{g})$ & MS & $\mathrm{R}$ & $\mathrm{R}$ & $\mathrm{R}$ & $\mathrm{S}$ & $\mathrm{R}$ & $\mathrm{R}$ & $\mathrm{R}$ \\
\hline Vancomycin $(30 \mu \mathrm{g})$ & $\mathrm{R}$ & $\mathrm{S}$ & $\mathrm{R}$ & $\mathrm{R}$ & $\mathrm{R}$ & $\mathrm{R}$ & $\mathrm{R}$ & $\mathrm{R}$ \\
\hline
\end{tabular}

S, sensitive; R, resistant; MS, moderately sensitive. 
Table 5. Prevalence of Microorganisms (Grown on Brain-Heart Agar) or Lactobacillus Sp. (Grown on MRS Agar) in Samples of Mesenteric Lymph Nodes, Spleen, and Liver from the Animals Treated with the Selected Lactobacillus Strains

\begin{tabular}{|c|c|c|c|c|c|c|}
\hline & \multicolumn{2}{|c|}{ Mesenteric lymph nodes } & \multicolumn{2}{|c|}{ Spleen } & \multicolumn{2}{|c|}{ Liver } \\
\hline & $B H(\%)$ & $\operatorname{MRS}(\%)$ & $B H(\%)$ & $\operatorname{MRS}(\%)$ & $B H(\%)$ & $\operatorname{MRS}(\%)$ \\
\hline Vehicle & $11 / 11(100)$ & $2 / 11(18)$ & $9 / 11(82)$ & $2 / 11(18)$ & 7/11 (64) & 0/11 (0) \\
\hline LGG & $8 / 8(100)$ & $1 / 8$ & $4 / 8(50)$ & $0 / 8(0)$ & $5 / 8(62.5)$ & $0 / 8(0)$ \\
\hline Lp299v & $7 / 7$ (100) & $0 / 7(0)$ & $3 / 7$ (43) & $0 / 7(0)$ & $2 / 7$ (29) & $0 / 7(0)$ \\
\hline $\mathrm{N}-221$ & $4 / 8(50)$ & $4 / 8(50)$ & $3 / 8(37.5)$ & $3 / 8(37.5)$ & $8 / 8 *(100)$ & $4 / 8 *(50)$ \\
\hline QF-60-2 & $5 / 7(71)$ & $0 / 7(0)$ & $3 / 7$ (43) & $0 / 7(0)$ & $5 / 7(71)$ & $0 / 7(0)$ \\
\hline $45 \mathrm{~B}$ & $6 / 6(100)$ & $1 / 6(17)$ & $5 / 6(83)$ & $1 / 6(17)$ & $5 / 6(83)$ & $0 / 6(0)$ \\
\hline N145 & $6 / 7(86)$ & - & 6/7 (86) & $0 / 7(0)$ & $7 / 7$ (100) & $0 / 7$ (0) \\
\hline 20 & $6 / 7(86)$ & 1/7 (14) & $6 / 7(86)$ & $1 / 7$ (14) & $5 / 7(71)$ & $1 / 7$ (14) \\
\hline
\end{tabular}

$* P<.05$; Fisher exact test.

$\mathrm{BH}$, brain heart; MRS

due to their fermentative metabolism that produces organic acids such as lactic acid, resulting in $\mathrm{pH}$ values lower than 4.5 in the fermented products where they are found. In addition, some of them are natural inhabitants of the small intestine and are adapted to the presence of bile salts. Our results show that about $24 \%$ of the strains evaluated were tolerant to artificial gastric juice, $\mathrm{pH} 2.0$, and to $0.4 \%$ bile salts, independently of their origin. The range of tolerance of Lactobacillus spp. to gastric conditions and bile salts described in the literature is rather broad, probably depending on the variations in the methods used, as previously stated. For example, $8.1 \%$ of the strains isolated from infant feces, ${ }^{17} 16.9 \%$ of these from infant feces or kimshi, ${ }^{18}$ and $20.7 \%$ of those from dairy products ${ }^{19}$ were resistant to gastric conditions and bile salts, similarly to the results observed in this study.

The adhesion of the probiotic strains to the epithelial cells overlying the mucosa of the stomach, small intestine, and colon is another important aspect that allows them to colonize temporarily in the gastrointestinal tract and exert their health-promoting effects, as well as preventing the adhesion of pathogens to the epithelium. ${ }^{18,20,21}$ Maragkoudakis et $a l .{ }^{19}$ recently observed that more than $34 \%$ of the 29 strains of Lactobacillus isolated from dairy products showed adhesion rates higher than $2.5 \%$, and as high as $25 \%$ for some of them. It must be remembered that increased adherence to the intestinal mucosa may also potentiate bacterial translocation and virulence. ${ }^{22}$ In our study, an adhesion rate greater than $2.5 \%$ was observed in $12 \%$ of the strains cocultured with intestinal cells and in $24 \%$ of these cocultured with gastric cells, similar to those observed with the widely consumed probiotic L. johnsonii NCC533.

In addition to their survival in the gastrointestinal tract, probiotics must display specific activities supporting their health-promoting effects. In this study, we evaluated the antibacterial activity of the Lactobacillus strains against the gastric pathogen $H$. pylori, in addition to their antioxidant and anti-inflammatory activities. $H$. pylori is a highly prevalent pathogen that colonizes the gastric mucosa and induces a chronic inflammation (gastritis). It is currently recognized as a major etiological agent of gastroduodenal ulcers and a risk factor for some common forms of gastric cancer. ${ }^{23}$ The treatment of gastric ulcers involves the administration of associations of two or three antibiotics and proton pump inhibitors and is mainly focused to the symptomatic patients; however, this treatment is not completely efficient due to the development of antibiotic resistance in the bacteria or to the lack of patient compliance. The antibiotic treatment, in addition, causes adverse effects and is expensive. Probiotics have been proposed as an interesting tool for the dietary management of asymptomatic colonized subjects in whom antibiotic treatment is not recommended or to increase the efficiency of the eradication treatment or decrease its side effects in colonized symptomatic patients. The antagonist effects of probiotics for $H$. pylori have been extensively reviewed ${ }^{24}$ and are mainly associated to the capacity of the strains to produce bacteriocins, as described for $L$. johnsonii NCC533. ${ }^{25}$ Our results confirm L. johnsonii NCC533 as the most efficient probiotic strain with anti- $H$. pylori activity compared with $L$. rhamnosus GG and L. plantarum $299 \mathrm{v}$; in addition, they show that $17 \%$ of the strains assayed in the study interfered with the pathogen growth and/or its urease activity. More studies with these strains are necessary to determine the eventual involvement of bacteriocins.

Inflammation and oxidative stress are phenomena frequently associated in pathological conditions such as infections (including those caused by $\mathrm{H}$. pylori), inflammatory and autoimmune diseases, and cancer and metabolic disturbances. Oxidative stress is related to the increased production of free radicals and/or the decrease of antioxidant defenses. It has been proposed that some strains of Lactobacillus may represent sources of dietary antioxidants ${ }^{26,27}$ because of their high content of free-radical scavengers such as glutathione, enzymes such as superoxide dismutase or catalase, or due to their ability to chelate pro-oxidant metals (iron, copper). Our results show that some of the strains evaluated exerted better anti-inflammatory and/or antioxidant activities than these exerted by the probiotic strains used as positive control, suggesting that they could positively modulate inflammatory processes in vivo. In contrast with these results, we also observed than some strains 
were able to increase IL- 8 release by TNF- $\alpha$-stimulated HT-29 cells; similar findings have also been previously described by Vizoso Pinto et al. ${ }^{28}$

Five strains were finally selected in this study according to their high levels of antibacterial, antioxidant, anti-inflammatory activity, and/or adhesion, compared with the control strains. These strains were subsequently genotyped, showing that four of them belonged to the L. rhamnosus species and one to the L. plantarum species. It is noteworthy that many of the widely commercially available probiotics are strains of L. rhamnosus, such as $L$. rhamnosus GG, L. rhamnosus HN001, L. rhamnosus Lcr35, or L. rhamnosus GR-1. Finally, the safety of these strains was evaluated in mice. This is a particularly important point as some cases of endocarditis or septicemia induced by Lactobacilli or bifidobacteria have been described in the recent decades, drawing attention to the real safety of probiotics. ${ }^{29-32}$ Our results show that the acute administration of high numbers of the selected strains for 1 week does not alter the well-being and weight gain of the animals, nor does it affect the integrity of their intestinal mucosa. The hematological parameters were not affected by the administrations of the selected probiotic strains, with the exception of L. plantarum N221, which significantly decreased the white cell concentration. Bacterial translocation was also evaluated. Mesenteric lymph nodes represent a relevant barrier to the passage of bacteria from the intestinal lumen to the systemic circulation. The presence of bacteria at this level as well as in the spleen and liver has been widely described in mice, ${ }^{33}$ but this finding does not seem to have a pathological significance.

Our results indicate that in general, bacterial translocation in the experimental groups receiving the selected probiotic strains was not different compared with the control group or the groups fed L. plantarum $299 \mathrm{v}$ or L. rhamnosus GG. However, a greater prevalence of liver translocation was observed in the animals administered the L. plantarum N221, suggesting that the probability of side effects with this strain could be higher than with the other strains.

In conclusion, out of 421 strains of Lactobacillus spp. isolated from plants, goat cheese, human stools, and milk samples, 102 were selected for their resistance to gastric conditions and bile salts. These were evaluated according to their anti-H. pylori, anti-inflammatory, antioxidant, and adhesive properties and the five most efficient were subsequently genotyped and their safety evaluated in mice. Four strains of L. rhamnosus were found to be safe and could be used in human studies.

\section{AUTHOR DISCLOSURE STATEMENT}

No competing financial interests exist.

\section{REFERENCES}

1. Dunne C, O'Mahony L, Murphy L, et al.: In vitro selection criteria for probiotic bacteria of human origin: Correlation with in vivo findings. Am J Clin Nutr 2001;73:386S-392S.
2. Dubos C, Vega N, Carvallo C, et al.: Identification of Lactobacillus spp. in colostrum from Chilean mothers. Arch Latinoam Nutr 2011;61:66-68.

3. Food and Agriculture Organization of the United Nations (FAO): Health and Nutritional Properties of Probiotics in Food Including Powder Milk with Live Lactic Acid Bacteria. www.who.int foodsafety/publications/fs_management/en/probiotics.pdf (2001).

4. Figueroa-González I, Quijano G, Ramírez G, Cruz-Guerrero A: Probiotics and prebiotics-perspectives and challenges. J Sci Food Agric 2011;91:1341-1348.

5. Garrido D, Suau A, Pochart P, Cruchet S, Gotteland M: Modulation of the fecal microbiota by the intake of a Lactobacillus johnsonii La1-containing product in human volunteers. FEMS Microbiol Lett 2005;248:249-256.

6. Brunser O, Figueroa G, Gotteland M, et al.: Effects of probiotic or prebiotic supplemented milk formulas on fecal microbiota composition of infants. Asia Pac J Clin Nutr 2006;15:368376

7. Brunser O, Gotteland M, Cruchet S, Figueroa G, Garrido D, Steenhout P: Effect of a milk formula with prebiotics on the intestinal microbiota of infants after an antibiotic treatment. Pediatr Res 2006;59:451-456.

8. Caceres P, Montes S, Vega N, Cruchet S, Brunser O, Gotteland M: Effects of Lactobacillus rhamnosus HN001 on acute respiratory infections and intestinal secretory $\operatorname{IgA}$ in children. $J P e$ diatr Infect Dis 2010;5:353-362.

9. Ko JS, Yang HR, Chang JY, Seo JK: Lactobacillus plantarum inhibits epithelial barrier dysfunction and interleukin-8 secretion induced by tumor necrosis factor-alpha. World $J$ Gastroenterol 2007; 13:1962-1965.

10. Cao G, Alessio HM, Cutler RG: Oxygen-radical absorbance capacity assay for antioxidants. Free Radic Biol Med 1993;14:303311.

11. Zhou JS, Shu Q, Rutherfurd KJ, Prasad J, Gopal PK, Gil HS: Acute oral toxicity and bacterial translocation studies on potentially probiotic strains of lactic acid bacteria. Food Chem Toxicol 2000;38:153-161.

12. Charteris WP, Kelly PM, Morelli L, Collins JK: Antibiotic susceptibility of potentially probiotic Lactobacillus species. J Food Prot 1998;61:1636-1643.

13. Zhou JS, Pillidge CJ, Gopal PK, Gill HS: Antibiotic susceptibility profiles of new probiotic Lactobacillus and Bifidobacterium strains. Int J Food Microbiol 2005;98:211-217.

14. Zhou JS, Shu Q, Rutherfurd KJ, et al.: Safety assessment of potential probiotic lactic acid bacterial strains Lactobacillus rhamnosus HN001, Lb. acidophilus HN017, and Bifidobacterium lactis HN019 in BALB/c mice. Int J Food Microbiol 2000;56:87-96.

15. International Scientific Association for Probiotics and Prebiotics (ISAPP): Clarification of the Definition of a Probiotic. www .isapp.net/docs/ProbioticDefinition.pdf (2009).

16. Gueimonde M, Salminen S: New methods for selecting and evaluating probiotics. Dig Liver Dis 2006;38:S242-S247.

17. Kirtzalidou E, Pramateftaki P, Kotsou M, Kyriacou A: Screening for Lactobacilli with probiotic properties in the infant gut microbiota. Anaerobe 2011;17:440-443.

18. Lee J, Yun HS, Cho KW, et al:: Evaluation of probiotic characteristics of newly isolated Lactobacillus spp.: Immune modulation and longevity. Int J Food Microbiol 2011;148:80-86.

19. Maragkoudakis PA, Zoumpopoulou G, Miaris C, Kalantzopoulos G, Pot B, Tsakalidou E: Probiotic potential of Lactobacillus 
strains isolated from dairy products. Int Dairy J 2006;16:189_ 199.

20. Lee NK, Yun CW, Kim SW, Chang HI, Kang CW, Paik HD: Screening of Lactobacilli derived from chicken feces and partial characterization of Lactobacillus acidophilus A12 as an animal probiotics. J Microbiol Biotechnol 2008;18:338-342.

21. Vesterlund S, Paltta J, Karp M, Ouwehand AC: Measurement of bacterial adhesion-in vitro evaluation of different methods. J Microbiol Methods 2005;60:225-233.

22. Apostolou E, Kirjavainen PV, Saxelin M, et al:: Good adhesion properties of probiotics: A potential risk for bacteremia? FEMS Immunol Med Microbiol 2001;31:35-39.

23. Backert S, Clyne M: Pathogenesis of Helicobacter pylori infection. Helicobacter 2011;16:19-25.

24. Gotteland M, Brunser O, Cruchet S: Systematic review: Are probiotics useful in controlling gastric colonization by Helicobacter pylori? Aliment Pharmacol Ther 2006;23:10771086.

25. Michetti P, Dorta G, Wiesel PH, et al.: Effect of whey-based culture supernatant of Lactobacillus acidophilus (johnsonii) La1 on Helicobacter pylori infection in humans. Digestion 1999;60: 203-209.

26. Martarelli D, Verdenelli MC, Scuri S, et al.: Effect of a probiotic intake on oxidant and antioxidant parameters in plasma of athletes during intense exercise training. Curr Microbiol 2011;62:16891696.

27. Saide JA, Gilliland SE: Antioxidative activity of Lactobacilli measured by oxygen radical absorbance capacity. J Dairy Sci 2005;88:1352-1357.

28. Vizoso Pinto MG, Rodriguez Gómez M, Seifert, S, Watzl B, Holzapfel WH, Franz CM: Lactobacilli stimulate the innate immune response and modulate the TLR expression of HT29 intestinal epithelial cells in vitro. Int J Food Microbiol 2009;133:86-93.

29. Borriello SP, Hammes WP, Holzapfel W, et al.: Safety of probiotics that contain Lactobacilli or bifidobacteria. Clin Infect Dis 2003;36:775-780

30. Cannon JP, Lee TA, Bolanos JT, Danziger LH: Pathogenic relevance of Lactobacillus: A retrospective review of over 200 cases. Eur J Clin Microbiol Infect Dis 2005;24:31-40.

31. Salminen MK, Rautelin H, Tynkkynen S, et al.: Lactobacillus bacteremia, species identification, and antimicrobial susceptibility of 85 blood isolates. Clin Infect Dis 2006;42:35-44.

32. Vankerckhoven V, Huys G, Vancanneyt M, et al.: Biosafety assessment of probiotics used for human consumption: Recommendations from the EU-PROSAFE project. Trends Food Sci Technol 2008;19:102-114.

33. Hale P, Hill A: The recovery of Lactobacillus sp. from the livers of healthy mice. Lab Anim 1973;7:119-124. 


\section{AUTHOR QUERY FOR JMF-2013-0030-VER9-GOTTELAND_1P}

AU1: Please review all authors' surnames for accurate indexing citations.

AU2: Please check the affiliation of all the authors.

AU3: Please check whether the sentence "Supported by Innova-Corfo 07CN13PZT-13." can be included under the Acknowledgment section.

AU4: Key words are taken from the pdf. Please check.

AU5: Please define MRS, DMEM, and CLSI.

AU6: Please expand UFC and MRS.

AU7: For clarity, please convert to SI units for mass concentration $(\mathrm{g} / \mathrm{mL})$, or change to weight percent [\% (w/w)].

AU8: Please provide last accessed date for refs. 3 and 15.

AU9: Please mention what superscript "a" indicates in Table 3 footnote. 